\title{
Thermo-oxidation of cholesterol: effect of the unsaturation degree of the lipid
}

matrix

Diana Ansorena $^{\mathrm{a}}$, Blanca Barriuso ${ }^{\mathrm{a}}$, Vladimiro Cardenia ${ }^{\mathrm{b}}$, Iciar Astiasarán ${ }^{\mathrm{a}}$, Giovanni Lercker $^{c}$, Maria Teresa Rodriguez-Estrada ${ }^{c}$

${ }^{a}$ Departamento de Ciencias de la Alimentación y Fisiología, Facultad de Farmacia, Universidad de Navarra, C/ Irunlarrea s/n, 31008 Pamplona, Spain bbarriuso@alumni.unav.es; iastiasa@unav.es

${ }^{\mathrm{b}}$ Interdepartmental Centre for Agri-food Industrial Research, Alma Mater StudiorumUniversità di Bologna, Piazza Goidanich 60, 47521 Cesena (FC), Italy vladimiro.cardenia3@unibo.it

${ }^{\mathrm{c}}$ Department of Agricultural and Food Sciences, Alma Mater Studiorum-Università di Bologna, Viale G. Fanin 40, 40127 Bologna, Italy giovanni.lercker@unibo.it; maria.rodriguez@unibo.it

* Corresponding author: email:dansorena@unav.es; telephone: 0034-948425600-6263

Publicado en: Ansorena D, Barriuso B, Cardenia V, Astiasaran I, Lercker G, RodriguezEstrada MT. Thermo-oxidation of cholesterol: effect of the unsaturation degree of the lipid matrix. Food Chem 20132013 Dec 1 (Epub 2013 May 24);141(3):2757-2764 


\begin{abstract}
The influence of the unsaturation degree of different triacylglycerols (tristearin, triolein, trilinolein and trilinolenin) on cholesterol oxidation at $180^{\circ} \mathrm{C}$, was evaluated. Cholesterol degraded faster when heated alone than in presence of triacylglycerols; moreover, the more unsaturated the matrix, the slower the degradation of cholesterol. Both cholesterol and triacylglycerols degradation fit a first order kinetic model $\left(\mathrm{R}^{2}>0.9\right)$, except for the tristearin sample. Cholesterol oxidation products (COPs) and peroxides were formed during the heating treatment. The presence of any type of lipid matrix postponed and decreased the maximum concentration of both oxidation parameters. Maximum total COPs concentrations were achieved at $20 \mathrm{~min}$ in neat cholesterol, $120 \mathrm{~min}$ in tristearin and triolein and $180 \mathrm{~min}$ in polyunsaturated matrix samples. 7-ketocholesterol was the main COP in most cases during the whole heating treatment. Both the presence of triacylglycerols and their unsaturation degree inhibited cholesterol thermooxidation at $180^{\circ} \mathrm{C}$.
\end{abstract}

Keywords: Thermoxidation, cholesterol, triacylglycerols, unsaturation degree, peroxides 


\section{HIGHLIGHTS}

1- The presence of triacylglycerols slowed down cholesterol degradation at $180^{\circ} \mathrm{C}$.

2- The presence and unsaturation degree of the lipid matrix delayed the COPs formation

3- Significantly higher PV was found when cholesterol was heated in absence of TAG.

4- Both cholesterol and triacylglycerol degradation fit a first order kinetic model. 


\section{INTRODUCTION}

Cholesterol present in animal food products has been reported to degrade under certain conditions, such as high temperature, long-term storage and/or light exposure (Mazalli \& Bragagnolo, 2007; Saldanha \& Bragagnolo, 2008; Boselli, Cardenia, \& Rodriguez-Estrada, 2012; Cardenia, Rodriguez-Estrada, Baldacci, Savioli, \& Lercker, 2012). In this process, cholesterol oxidation products (known as COPs) are formed among other compounds. COPs have been related to atherosclerosis, mutagenesis, neurodegenerative diseases and some other harmful effects for human health (OtaeguiArrazola, Menéndez-Carreño, Ansorena, \& Astiasarán, 2010).

Food matrix and its chemical composition are key factors in cholesterol oxidation. In particular, the unsaturation degree of the lipid fraction may play an important role towards cholesterol degradation and COPs formation. Recent studies carried out in real food systems (horse meat and eggs) concluded that higher unsaturation degree of the lipid matrix promotes cholesterol oxidation (Pignoli, Rodríguez-Estrada, Mandrioli, Barbanti, Rizzi, \& Lercker, 2009; Boselli, Rodríguez-Estrada, Ferioli, Caboni, \& Lercker, 2010), due to the generation of a pro-oxidant environment with the presence of free radicals and hydroperoxides (Ohshima, 2002). Previous work (Kim \& Nawar, 1991) stated that, during heating, the presence of unsaturated fatty acids should promote cholesterol oxidation more readily than the presence of saturated fatty acids. However, in photoxidized model systems containing fatty acid methyl esters and cholesterol, $\mathrm{Hu}$ and Chen (2002) observed that stearate resulted in a higher loss of cholesterol than linoleate and docosahexaenoate.

As it has been shown, there is no general agreement on the role of the unsaturation degree of fatty acids in cholesterol oxidation, as some authors have concluded that other 
factors could be strongly decisive on the oxidative behavior, such as temperature, heating time (Soupas, Juntunen, Lampi, \& Piironen, 2004), being the effect of fatty acids on cholesterol oxidation unlikely related to their unsaturation level (Xu, Sun, Liang, Yang, \& Chen, 2011).

Most of the studies dealing with cholesterol oxidation have been directly performed on food products (Boselli et al., 2012; Orczewska-Dudek, Bederska-Lojewska, Pieszka, \& Pietras, 2012; Vicente \& Sampaio, 2012; Cardenia, Rodríguez-Estrada, Boselli, \& Lercker, 2013), so interferences with other components of the sample are assumed. On the other hand, model systems have been recognized as a good means to obtain precise information about kinetic behavior of sterols subjected to heating (Chien, Hsu, Inbaraj, \& Chen, 2010; Barriuso, Otaegui-Arrazola, Menéndez-Carreño, Astiasarán, \& Ansorena, 2012). Up to now, few of them have directly tackled the effect of lipid unsaturation. Various strategies, such as purifying vegetable oils (Soupas et al., 2004) or using synthetic free fatty acids (Kim \& Nawar, 1991; Xu et al., 2011), have been applied as an attempt to minimize the influence of other interfering factors different from the lipid unsaturation degree. However, to our knowledge, no information is available on the effect of synthetic triacylglycerols (TAG), which could be different from that of free fatty acids, since the later are more prone to oxidation and the former are more abundant in food. For a better understanding of the oxidative process, more studies with model systems would be required, so that a clear trend can be elucidated, with no interferences.

In this context, the aim of the present study was to evaluate the influence of the unsaturation degree of different TAG (tristearin (TS), triolein (TO), trilinolein (TL) and trilinolenin (TLn)) on cholesterol oxidation susceptibility and COPs formation, under heating conditions. 


\section{MATERIAL AND METHODS}

\subsection{Material and reagents}

All solvents used were analytical grade. Reagents were supplied by Carlo Erba Reagenti (Rodano, Italy) and Merck (Darmstadt, Germany). Commercial standards of triacylglycerols (TS, TO, TL and TLn) were purchased from Nu-Check (Elysian, MN).

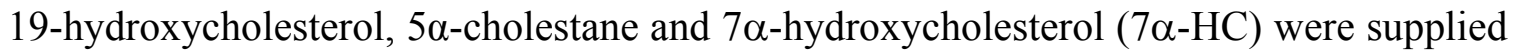
by Steraloids (Newport, RI, USA). Cholesterol, 7 $\beta$-hydroxycholesterol (7 $\beta$-HC), 5,6 $\alpha$ cholesterol epoxide ( $\alpha$-CE), 5,6 $\beta$-cholesterol epoxide ( $\beta$-CE), 3,5,6-cholestanetriol $(\mathrm{CT})$ and 7-ketocholesterol (7-KC) were purchased from Sigma (St. Louis, MO, USA). The purity of sterols and COPs standards was controlled by GC-FID. $\mathrm{NH}_{2}$ solid-phase extraction (SPE) cartridges $(500 \mathrm{mg} / 3 \mathrm{~mL}$ Strata cartridges) from Phenomenex (Torrence, CA, USA), were utilized for COPs purification. The silylation mixture was prepared with dried pyridine, hexamethyldisilazane and trimethylchlorosilane at a ratio of $5: 2: 1$ by volume.

\subsection{Heating treatment}

For each type of TAG, a stock solution of TAG:cholesterol (100:1) was prepared in chloroform. Samples $(200 \mathrm{mg})$ were put into open glass tubes $(18 \mathrm{~mm}$ diameter, $100 \mathrm{~mm}$ height), dried under $\mathrm{N}_{2}$ stream $\left(40{ }^{\circ} \mathrm{C}\right)$ until constant weight. The unsealed tubes were then placed open in an oven (Memmert GmbH $+\mathrm{Co} . \mathrm{KG}$, Nurnberg, Germany) previously heated at $180^{\circ} \mathrm{C}$, in duplicate.). They were taken out from the oven after different heating times $(0,5,10,20,30,60,90,120,180$ and $240 \mathrm{~min})$ and cooled down for $2 \mathrm{~min}$. One $\mathrm{mL}$ of chloroform was added to each tube, and samples were shaken vigorously for 40 
sec and kept under $-20{ }^{\circ} \mathrm{C}$ until analysis. The heating experiment was run twice. TL and TLn mixtures sampled at 240 min were not analyzed due to the incomplete solubility in chloroform. A similar experimental set up was applied to cholesterol alone (2 mg/tube).

\subsection{Analysis of remaining cholesterol and TAG}

An aliquot $(50 \mu \mathrm{L})$ equivalent to approximately $10 \mathrm{mg}$ of the heated sample were transferred to a test tube. The solvent was evaporated and the exact lipid weight was registered. Chloroform $(1 \mathrm{~mL})$ and $5 \alpha$-cholestane as internal standard (IS, $50 \mu \mathrm{L}$ of a 1 $\mathrm{mg} / \mathrm{mL}$ solution) were added. The mixture was vigorously shaken and $1 \mu \mathrm{L}$ was injected into a TRACE gas chromatograph coupled to a flame ionization detector (GC-FID) (Thermo Finnigan, Milan, Italy), which was interfaced with a computerized system for data acquisition (Chromcard Data System, ver. 2.3.1, Fisons Instruments). A SE52 MEGA fused-silica column (10 m x $0.32 \mathrm{~mm}$ x $0.1 \mu \mathrm{m})$ (Mega s.n.c., Legnano (Mi), Italy) coated with 5\% phenyl-95\% dimethyl-polysiloxane, was used. The oven temperature was programmed from $100{ }^{\circ} \mathrm{C}$ to $350{ }^{\circ} \mathrm{C}$ at $6{ }^{\circ} \mathrm{C} / \mathrm{min}$, and kept at $350{ }^{\circ} \mathrm{C}$ for $20 \mathrm{~min}$; the injector and detector temperatures were both set at $325^{\circ} \mathrm{C}$. Helium was used as carrier gas at a flow of $1.0 \mathrm{~mL} / \mathrm{min}$; the split ratio was 1:20. Areas for cholesterol, TAG and IS were integrated. Remaining cholesterol and TAG for each time of analysis were calculated considering the initial amount $(t=0)$ as $100 \%$.

\subsection{COPs purification and analysis}

To determine COPs, it was first necessary to remove TAG and cholesterol from heated samples by $\mathrm{NH}_{2}$-SPE, as suggested by Rose-Sallin, Hugget, Bosset, Tabacchi and Fay (1995). COPs were eluted with acetone, and then silylated by adding $0.1 \mathrm{~mL}$ of the 
derivatizing mixture (pyridine:hexamethyldisilazane:trimethylchlorosilane, 5:2:1, v/v/v) at $40{ }^{\circ} \mathrm{C}$ for $15 \mathrm{~min}$ (Sweeley, Bentley, Makita, \& Wells, 1963); thereafter, silylated COPs were dried under nitrogen stream and dissolved in $100 \mu \mathrm{L}$ of $n$-hexane. One $\mu \mathrm{L}$ of the silylated COPs was analyzed by Fast GC-MS, as suggested by Cardenia et al. (2012). Fast GC/MS analysis was performed using a GC Shimadzu QP 2010 Plus (Kyoto, Japan) equipped with a split-splitless injector and coupled to a EI mass spectrometric detector. A fused silica capillary column Restek RTX-5 (10 m x $0.1 \mathrm{~mm}$ i.d. x $0.1 \mu \mathrm{m}$ film thickness; Bellafonte, PA, USA) coated with 95\% dimethyl- and 5\% diphenyl-polysiloxane, was used. The temperature was programmed from $250{ }^{\circ} \mathrm{C}$ to $325{ }^{\circ} \mathrm{C}$ at $20{ }^{\circ} \mathrm{C} / \mathrm{min}$. The injector temperature was set at $325^{\circ} \mathrm{C}$ and the ion source temperature was set at $230{ }^{\circ} \mathrm{C}$. Helium was used as the carrier gas and linear velocity was $43 \mathrm{~cm} / \mathrm{sec}$. Helium inlet pressure was $426.7 \mathrm{kPa}$. The injection was performed in the split system at 1:50 splitting ratio. The electron energy was $70 \mathrm{eV}$. A mass range from $\mathrm{m} / \mathrm{z} 40$ to 650 was scanned at a rate of $3333 \mathrm{amu} / \mathrm{sec}$, which corresponded to 0.2 event time.

The acquisition and integration modes were Full Scan (TIC) and Single Ion Monitoring (SIM), respectively. COPs were recognized and quantified by their corresponding characteristic ions with a high abundance: m/z 353 (19-HC); m/z 456 (7 $\alpha$ -

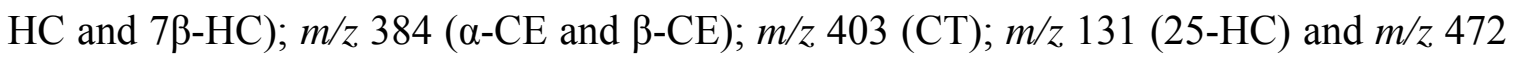
(7-KC). COPs quantification was performed by using calibration curves in the SIM mode (Cardenia et al., 2012), plotting the ratio of a COP area to the internal standard area as function of the ratio of COP standard concentration to internal standard concentration. The COPs concentration range of the calibration curves was $0.01-45 \mu \mathrm{g} / \mathrm{mL}\left(\mathrm{r}^{2}=0.996-\right.$ 1.000). GC-MS LOD and LOQ of COPs were 2.18-5.07 ng/mL and 6.93-16.90 ng/mL, respectively (Cardenia et al., 2012). 


\subsection{Peroxides analysis}

Peroxide value (PV) was determined in $10 \mathrm{mg}$ of sample, as suggested by Shantha and Decker (1994). Briefly, this method is based on the ability of peroxides to oxidize ferrous ions to ferric ions, which react with ammonium thiocyanate and give rise to the formation of a colored complex. PV was evaluated at $500 \mathrm{~nm}$ with a double-beam UVvisible spectrophotometer (Jasco model V-550, Jasco International, Tokyo, Japan), and it was calculated from the absorbance. For the quantitative determination of PV, a Fe(III) standard calibration curve was used with a concentration range of $0.1-5 \mu \mathrm{g} / \mathrm{mL}$ ( $\mathrm{y}=$ $\left.\mathrm{y}=0.0311 \mathrm{x}-0.0003 ; \mathrm{r}^{2}=0.999\right)$. PV was expressed as meq $\mathrm{O}_{2} / \mathrm{kg}$ of fat. Three replicates were run per sample.

\subsection{Statistical analysis}

For the statistical analysis of the data, SPSS 15.0 program (SPSS, Inc., Chicago, IL, U.S.A.) was used. Mean and standard deviation of data obtained from each replicate were calculated. One factor ANOVA, with Tukey's post hoc multiple comparisons $(p<0.05)$, was applied to evaluate the significant differences on cholesterol and COPs amounts over time and among samples containing different TAG. For the mathematical modelling of cholesterol and TAG degradation, the non-linear regression analysis was used. Finally, correlations were assessed by Pearson's correlation test.

\section{RESULTS AND DISCUSSION}

\subsection{Unreacted TAG and cholesterol trends}


The remaining amounts of TAG and cholesterol were followed along the heating treatment. In the case of TAG, the higher the unsaturation degree, the faster the drop rate (Fig. 1); in fact, after 90-min heating, 74, 47, 25 and 25\% of the initial TAG content was observed in the TS, TO, TL and TLn samples, respectively.

Cholesterol degraded faster when it was heated alone than in the presence of TAG. This trend could be due to the fact that TAG allowed cholesterol dilution, as well as it exerted physical protection, reducing contact with oxygen, and thus, limiting oxidation (Yen, Lu, Inbaraj, \& Chen, 2011). Furthermore, TAG would also compete with cholesterol for oxidation. Specifically, it suffered progressively lesser degradation in the presence of TS, TO, TL and TLn, as it can be seen from the final remaining cholesterol concentration in each case, which was $0,13,34$ and $54 \%$ of the initial amounts, respectively.

Comparing the degradation rate of cholesterol with that observed for TAG, it can be noted that cholesterol decreased much faster than TAG in the TS matrix, whereas it was slower in polyunsaturated matrices. However, a similar degradation rate was noticed between TAG and cholesterol in TO matrix, with a very high correlation coefficient between the two decays ( $\mathrm{R}$ Pearson $=0.994)$, as cholesterol is a monounsaturated biomolecule that exhibits an analogous oxidative stability as monounsaturated fatty acids (i.e. oleic acid). Therefore, it can be concluded that unsaturated TAG are degraded earlier than cholesterol, whereas the saturated TAG was much more stable. This can be explained by the fact that unsaturated fatty acids are more susceptible to oxidation than saturated ones, they compete with cholesterol for oxygen, and therefore could reduce its oxidation. Xu, Guan, Sun and Chen (2009) observed a similar situation when working with corn oil, lard and olive oil, even though, in that case, endogenous antioxidant 
compounds were also present. The present results suggest that, at $180^{\circ} \mathrm{C}$, the TAG unsaturation seemed to protect cholesterol against oxidation. In another work, CLA demonstrated to prevent cholesterol oxidation (Yen, Inbaraj, Chien, \& Chen, 2010); this antioxidant property was related to its high number of double bonds, so TAG unsaturation level could be behind the protective effect in the current study as well.

A kinetic evaluation of the TAG and cholesterol loss throughout the process was performed (Table 1). They all satisfactory fit a first order kinetic model, except for the TS:cholesterol sample, which showed the smallest values of correlation coefficient for both cholesterol and TAG adjustments.

Excluding TS samples behavior, the presence of any type of TAG moiety inhibited cholesterol degradation, as it can be deduced from the $k$ values. Moreover, the more unsaturated the matrix, the lower the constant $\left(0.009,0.005\right.$ and $0.004 \mathrm{~min}^{-1}$ for TO, TL and TLn matrices, respectively), which confirms that cholesterol degradation was slower in unsaturated than in saturated matrices. This trend was also corroborated by calculating molar concentrations of degraded cholesterol and fatty acids at $90 \mathrm{~min}$, that resulted in ratios of "degraded fatty acid/degraded cholesterol" of 4.8, 14.8, 25.8 and 35.4 for TS, TO, TL and TLn respectively. A similar trend towards unsaturation degree was found when cholesterol was photooxidized in the presence of fatty acid methyl esters $(\mathrm{Hu}$ $\&$ Chen, 2002), showing degradation rate constants of $0.0322,0.0152$ and 0.0198 day $^{-1}$ for stearic, linoleic and DHA, respectively, with a first order kinetics model.

On the other hand, the degradation rate of TAG increased with unsaturation degree, giving a maximum $k$ for TLn and a minimum $k$ for TS. Similar behavior towards unsaturation degree has been reported for fatty acid methyl esters subjected to photooxidation (Hu \& Chen, 2002; Chien, Lu, Hu, \& Chen, 2003). 


\subsection{COPs and peroxides formation}

The loss of cholesterol and TAG as a consequence of the oxidation process during heating, induced the formation of cholesterol oxidation products (COPs) and peroxides (PV) in the media. The presence of any type of lipid matrix postponed and decreased the maximum concentration of oxidation products (PV or COPs), as it can be observed in Figs. 2 and 3.

The maximum PV for cholesterol alone (176.44 meq $\mathrm{O}_{2} / \mathrm{Kg}$ lipids) was significantly higher $(p<0.05)$ than those achieved by the TAG-containing samples $(40$, 50, 55 and 49 meq $\mathrm{O}_{2} / \mathrm{Kg}$ lipids for TS, TO, TL, and TLn, respectively). In the case of unsaturated matrices, the apex was reached after $20 \mathrm{~min}$, with a slower increase for TO, as compared to polyunsaturated TAG. Also the PV decay was slower in TO, maintaining higher values throughout the heating treatment with respect to polyunsaturated matrices (Fig. 2b). In fact, TS slowed down the peroxide formation, reaching the maximum PV (39.68 meq $\mathrm{O}_{2} / \mathrm{Kg}$ lipids) after $90 \mathrm{~min}$ of treatment (Fig. 2a).

The maximum concentration of total COPs was achieved at different times of heating, depending on the TAG medium. The apex was reached at $20 \mathrm{~min}$ in neat cholesterol samples, $120 \mathrm{~min}$ in TS and TO matrix samples and $180 \mathrm{~min}$ in polyunsaturated matrix samples (Fig. 3). The maximum COPs levels found were 60.4, $57.3,50.7,35.7$ and $23.5 \mu \mathrm{g} / \mathrm{mg}$ cholesterol for cholesterol alone, TS, TO, TL and TLn medium, respectively. Comparing the four $\mathrm{TAG}+$ cholesterol mixtures, total COPs from TS were significantly higher than those detected for the rest of mixtures at every time of analysis up to $120 \mathrm{~min}$. At longer times, COPs from TO matrix reached higher levels than the rest of mixtures. In the case of polyunsaturated lipid matrices (TL and TLn), 180 min 
was the last point in which reliable data could be obtained, as polymerization prevented a good solubility of samples.

Slightly higher concentrations of COPs $(86,69,68$ and $53 \mu \mathrm{g} / \mathrm{mg}$ cholesterol) were found by $\mathrm{Xu}$ et al. (2011) for the same heating treatment conditions, using the corresponding free fatty acids (stearic, oleic, linoleic and linolenic acids) instead of TAG. Although they concluded that the oxidation promoting effect depended on the heating time rather than on the unsaturation degree, data showed that maximum total COPs achieved (at $90 \mathrm{~min}$, in that case) were also greater (around 20\%) for stearic acid than for unsaturated fatty acids. Studies carried out on esterified cholesterol showed that esterification affect both the rate of cholesterol oxidation and the amount of oxidation products, being this rate different depending on the unsaturation degree of the acyl moiety (Lehtonen, Kemmo, Lampi, \& Piironen, 2011; Lehtonen, Lampi, Riuttamäki, \& Piironen, 2012). On the other hand, studies performed in natural food matrices provide a wide diversity of results. In general, lower amounts of COPs are achieved when cooking technologies imply the use of an extra lipid source than when the food is prepared by other cooking methods (Echarte, Zulet, \& Astiasarán, 2001, Echarte, Ansorena, \& Astiasarán, 2003).

Considering individual COPs (Table 2), 7-KC was the main one in most cases during the whole heating treatment. It accounted for more than $40 \%$ of total COPs when cholesterol was heated alone $(\mathrm{t}=20 \mathrm{~min})$, and in the presence of TS and TO $(\mathrm{t}=120 \mathrm{~min})$; the maximum amounts of COPs were actually detected at these times. In TL and especially in TLn samples, a significant contribution of $7 \beta-\mathrm{HC}$ was also noticed at 180 min, when total COPs reached the apex. 25-HC and CT were the compounds formed in least amount, not exceeding $1.21 \mu \mathrm{g} / \mathrm{mg}$ cholesterol in all cases. 
7-hydroxy and 7-keto oxides are usually expected to be the major COPs (Grandgirard, Martine, Joffre, Juaneda, \& Berdeaux, 2004), at least during the first stages of oxidation. The decline of 7-hydroxy derivatives started before that of 7-KC in TS, TO and TLn samples (60 min vs. $120 \mathrm{~min}, 120 \mathrm{~min}$ vs. $180 \mathrm{~min}$, and $120 \mathrm{~min}$ vs. $180 \mathrm{~min}$ ). This might be attributed to the conversion from 7-hydroxy derivatives into such COP (Lee, Chien, \& Chen, 2006; Chen, Chien, Inbaraj, \& Chen, 2012).

Dominancy of $\beta$-epimer in both 7-hydroxy and epoxy derivatives was observed, which may be due to steric hindrance of the hydroxyl group at position 3 (Lee et al., 2006); other authors have also observed this trend (Lampi, Juntunen, Toivo, \& Piironen, 2002; Yen et al., 2010). Both epoxy compounds can give CT under acidic conditions (Lee et al., 2006). CT was formed at advanced stages of oxidation, when the epoxy compounds (and other compounds) had already started their decline. It was only found in cholesterol, TS and TL samples at very low amounts, so it may have been further converted to cholestan-3 $\beta, 5 \alpha, 6$-one through dehydrogenation (Chien, Huang, \& Chen, 2004). Negligible levels of triol compounds have previously been reported for vegetable oils and spreads, as well (Lampi et al., 2002; Conchillo, Cercaci, Ansorena, RodríguezEstrada, Lercker, \& Astiasarán, 2005).

In conclusion, these results demonstrated that both presence of TAGs and their unsaturation degree affect cholesterol thermooxidation at $180{ }^{\circ} \mathrm{C}$. In particular, an inhibitory effect of the lipid matrix against cholesterol degradation was found in these model systems; moreover, such effect seems to be further promoted by the unsaturation degree. Cholesterol oxidation rate might have also been affected by TAG physical arrangement and molecular hyndrance, as well as by chemical group interaction and the viscosity increase due to polymerization. 


\section{ACKNOWLEDGEMENTS}

We thank the "Programa Consolider-Ingenio 2010 CARNISENUSA CSD 200700016”, the "Proyecto AGL2008-01099/ALI"' (Ministerio de Ciencia e Innovación) and the basic reasearch funding (RFO 2010; Alma Mater Studiorum-Università di Bologna, Italy), for the financial support of this work. D. Ansorena is grateful to "Programa Salvador de Madariaga" (Ministerio de Educación, Gobierno de España) for the mobility grant received. V. Cardenia thanks for the research fellowship granted by the Interdepartmental Centre for Agri-food Industrial Research (Cesena, Italy). We also acknowledge to Stefano Savioli for his technical assistance. 


\section{REFERENCES}

Barriuso, B., Otaegui-Arrazola, A., Menéndez-Carreño, M., Astiasarán, I., \& Ansorena, D. (2012). Sterols heating: Degradation and formation of their ring-structure polar oxidation products. Food Chemistry, 135, 706-12.

Boselli, E., Cardenia, V., \& Rodriguez-Estrada, M. T. (2012). Cholesterol photosensitized oxidation in muscle foods. European Journal of Lipid Science and Technology, 114, 644-655.

Boselli, E., Rodriguez-Estrada, M. T., Ferioli, F., Caboni, M., \& Lercker, G. (2010). Cholesterol photosensitised oxidation of horse meat slices stored under different packaging films. Meat Science, 85, 500-505.

Cardenia, V., Rodriguez-Estrada, M. T., Baldacci, E., Savioli, S., \& Lercker, G. (2012). Analysis of cholesterol oxidation products by fast gas chromatography/mass spectrometry. Journal of Separation Science, 35, 424-430.

Cardenia, V., Rodriguez-Estrada, M. T., Boselli, E., \& Lercker, G. (2013). Cholesterol photosensitized oxidation in food and biological systems. Biochimie, 95, 473-481.

Chen, Y. C., Chien, J. T., Inbaraj, B. S., \& Chen, B. (2012). Formation and inhibition of cholesterol oxidation products during marinating of pig feet. Journal of Agricultural and Food Chemistry, 60, 173-179.

Chien, J., Hsu, D., Inbaraj, B., \& Chen, B. (2010). Integral kinetic model for studying quercetin degradation and oxidation as affected by cholesterol during heating. International Journal of Molecular Sciences, 11, 2805-2820. 
Chien, J. T., Huang, D. Y., \& Chen, B. H. (2004). Kinetic studies of cholesterol oxidation as inhibited by stearylamine during heating. Journal of Agricultural and Food Chemistry, 52, 7132-7138.

Chien, J., Lu, Y., Hu, P., \& Chen, B. (2003). Cholesterol photooxidation as affected by combination of riboflavin and fatty acid methyl esters. Food Chemistry, 81, 421-431.

Conchillo, A., Cercaci, L., Ansorena, D., Rodriguez-Estrada, M. T., Lercker, G., \& Astiasarán, I. (2005). Levels of phytosterol oxides in enriched and non-enriched spreads: Application of a thin-layer chromatography-gas chromatography methodology. Journal of Agricultural and Food Chemistry, 53, 7844-7850.

Echarte, M., Zulet, M. A., \& Astiasarán, I. (2001). Oxidation process affecting fatty acids and cholesterol in fried and roasted salmon. Journal of Agricultural and Food Chemistry, 49, 5662-5667.

Echarte, M., Ansorena, D., \& Astiasarán, I. (2003). Consequences of microwave heating and frying on the lipid fraction of chicken and beef patties. Journal of Agricultural and Food Chemistry, 51, 5941-5945.

Grandgirard, A., Martine, L., Joffre, C., Juaneda, P., \& Berdeaux, O. (2004). Gas chromatographic separation and mass spectrometric identification of mixtures of oxyphytosterol and oxycholesterol derivatives - application to a phytosterol-enriched food. Journal of Chromatography A, 1040, 239-250.

Hu, P. C., \& Chen, B. H. (2002). Effects of riboflavin and fatty acid methyl esters on cholesterol oxidation during illumination. Journal of Agricultural and Food Chemistry, 50, 3572-3578.

Kim, S., \& Nawar, W. (1991). Oxidative interactions of cholesterol with triacylglycerols. Journal of the American Oil Chemists' Society, 68, 931-934. 
Lampi, A., Juntunen, L., Toivo, J., \& Piironen, V. (2002). Determination of thermooxidation products of plant sterols. Journal of Chromatography B, 777, 83-92.

Lee, H., Chien, J., \& Chen, B. (2006). Formation of cholesterol oxidation products in marinated foods during heating. Journal of Agricultural and Food Chemistry, 54, 4873-4879.

Lehtonen, M., Kemmo, S., Lampi, A.M., \& Piironen,V. (2011). Effects of esterification on the formation and decomposition of steryl hydroperoxides. European Food Research and Technology, 232, 255-264.

Lehtonen, M., Lampi, A.M., Riuttamäki M. A., \& Piironen,V. (2012). Oxidtion reactions of steryl esters in a saturated lipid matrix. Food Chemistry, 134, 2030-2039.

Mazalli, M., \& Bragagnolo, N. (2007). Effect of storage on cholesterol oxide formation and fatty acid alterations in egg powder. Journal of Agricultural and Food Chemistry, 55, 2743-2748.

Ohshima, T. (2002). Formation and content of cholesterol oxidation products in seafood and seafood products. In R. Codony, G. P. Savage, P. C. Dutta, \& F. Guardiola (Eds.), Cholesterol and Phytosterol Oxidation Products: Analysis Occurrence and Biological Effects (pp. 187-203). Champaign, ILL, USA: AOCS Press.

Orczewska Dudek, S., Bederska Lojewska, D., Pieszka, M., \& Pietras, M. (2012). Cholesterol and lipid peroxides in animal products and health implications- A review. Annals of Animal Science, 12, 25-52.

Otaegui-Arrazola, A., Menéndez-Carreño, M., Ansorena, D., \& Astiasarán, I. (2010). Oxysterols: A world to explore. Food and Chemical Toxicology, 48, 3289-3303.

Pignoli, G., Rodriguez-Estrada, M. T., Mandrioli, M., Barbanti, L., Rizzi, L, \& Lercker, G. (2009). Effects of different rearing and feeding systems on lipid oxidation and 
antioxidant capacity of freeze-dried egg yolks. Journal of Agricultural and Food Chemistry, 57, 11517-11527.

Rose-Sallin, C., Huggett, A., Bosset, J., Tabacchi, R., \& Fay, L. (1995). Quantification of cholesterol oxidation-products in milk powders using [H-2(7)] cholesterol to monitor cholesterol autoxidation artifacts. Journal of Agricultural and Food Chemistry, 43, 935-941.

Saldanha, T., \& Bragagnolo, N. (2008). Relation between types of packaging, frozen storage and grilling on cholesterol and fatty acids oxidation in atlantic hake fillets (merluccius hubbsi). Food Chemistry, 106, 619-627.

Shantha, N., \& Decker, E. (1994). Rapid, sensitive, iron-based spectrophotometric methods for determination of peroxide values of food lipids. Journal of AOAC International, 77, 421-424.

Soupas, L., Juntunen, L., Lampi, A. M., \& Piironen, V. (2004). Effects of sterol structure, temperature, and lipid medium on phytosterol oxidation. Journal of Agricultural and Food Chemistry, 52, 6485-6491.

Sweeley, C., Bentley, R., Makita, M., \& Wells, W. (1963). Gas-Liquid chromatography of trimethylsilyl derivatives of sugars and related substances. Journal of the American Chemical Society, 85, 2497-2507.

Vicente, S. J. V., \& Sampaio, G. (2012). Oxidation of cholesterol in foods and its importance for human health. Food Reviews International, 28, 47-70.

Xu, G. H., Sun, J. L., Liang, Y. T., Yang, C., \& Chen, Z. Y. (2011). Interaction of fatty acids with oxidation of cholesterol and beta-sitosterol. Food Chemistry, 124, 162170. 
Xu, G., Guan, L., Sun, J., \& Chen, Z. (2009). Oxidation of cholesterol and beta-sitosterol and prevention by natural antioxidants. Journal of Agricultural and Food Chemistry, 57, 9284-9292.

Yen, T. Y., Inbaraj, B., Chien, J., \& Chen, B. (2010). Gas chromatography-mass spectrometry determination of conjugated linoleic acids and cholesterol oxides and their stability in a model system. Analytical Biochemistry, 400, 130-138.

Yen, T. Y., Lu, Y., Inbaraj, B. S., \& Chen, B. (2011). Cholesterol oxidation in lard as affected by CLA during heating- a kinetic approach. European Journal of Lipid Science and Technology, 113, 214-223. 
Table 1. Kinetic parameters for remaining cholesterol and TAG (in cholesterol alone and cholesterol + TAG mixtures) throughout the thermoxidation process at $180^{\circ} \mathrm{C}$

\begin{tabular}{lcccc}
\hline & \multicolumn{2}{c}{ Remaining cholesterol $^{\mathbf{a}}$} & \multicolumn{2}{c}{${\text { Remaining } \text { TAG }^{\mathbf{b}}}$} \\
& $k\left(\mathrm{~min}^{-1}\right)$ & $\mathrm{R}^{2}$ & $k\left(\mathrm{~min}^{-1}\right)$ & $\mathrm{R}^{2}$ \\
\hline Cholesterol (C) & 0.014 & 0.885 & --- & --- \\
$\mathrm{C}+\mathrm{TS}$ & 0.051 & 0.719 & 0.003 & 0.882 \\
$\mathrm{C}+\mathrm{TO}$ & 0.009 & 0.993 & 0.010 & 0.988 \\
$\mathrm{C}+\mathrm{TL}$ & 0.005 & 0.906 & 0.014 & 0.972 \\
$\mathrm{C}+\mathrm{TLn}$ & 0.004 & 0.911 & 0.014 & 0.972 \\
\hline
\end{tabular}

${ }^{a}$ First order kinetic model corresponding to $\ln \frac{\mathrm{chol}_{t}}{\mathrm{chol}_{0}}=-k \cdot t$

${ }^{\mathbf{b}}$ First order kinetic model corresponding to $\ln \frac{T A G_{t}}{T A G_{0}}=-k \cdot t$ 
Table 2. Concentration of COPs ( $\mu \mathrm{g} / \mathrm{mg}$ cholesterol) in cholesterol and cholesterol + TAG mixtures, during heating at $180^{\circ} \mathrm{C}$. 


\begin{tabular}{|c|c|c|c|c|c|c|c|c|c|c|}
\hline \multicolumn{11}{|c|}{ time (min) } \\
\hline & $\mathbf{0}$ & 5 & 10 & 20 & 30 & 60 & 90 & 120 & 180 & 240 \\
\hline \multicolumn{11}{|c|}{ Cholesterol } \\
\hline $7 \alpha-\mathrm{HC}$ & $0.10 \mathrm{a}^{*}$ & $0.20 \mathrm{a}$ & $0.96 \mathrm{ab}$ & $3.58 \mathrm{~b}$ & $2.42 \mathrm{ab}$ & $0.23 \mathrm{a}$ & $0.19 \mathrm{a}$ & $0.13 a$ & $0.00 \mathrm{a}$ & $0.00 \mathrm{a}$ \\
\hline 7及-HC & $0.12 \mathrm{a}$ & $0.27 \mathrm{a}$ & $1.36 \mathrm{ab}$ & $8.69 c$ & $5.52 b c$ & $1.00 \mathrm{ab}$ & $0.51 \mathrm{a}$ & $0.17 \mathrm{a}$ & $0.00 \mathrm{a}$ & $0.00 \mathrm{a}$ \\
\hline 及-EC & $0.00 \mathrm{a}$ & $0.35 \mathrm{a}$ & $1.22 \mathrm{a}$ & $3.81 \mathrm{~b}$ & $1.85 \mathrm{a}$ & $0.00 \mathrm{a}$ & $0.00 \mathrm{a}$ & $0.00 \mathrm{a}$ & $0.00 \mathrm{a}$ & $0.00 \mathrm{a}$ \\
\hline$\alpha-E C$ & $0.00 \mathrm{a}$ & $0.26 \mathrm{a}$ & $0.63 a$ & $5.50 \mathrm{~b}$ & $1.38 \mathrm{a}$ & $0.00 \mathrm{a}$ & $0.00 \mathrm{a}$ & $0.00 \mathrm{a}$ & $0.00 \mathrm{a}$ & $0.00 \mathrm{a}$ \\
\hline CT & $0.00 \mathrm{a}$ & $0.00 \mathrm{a}$ & $0.00 \mathrm{a}$ & $0.08 \mathrm{a}$ & $0.15 \mathrm{a}$ & $0.14 \mathrm{a}$ & $0.31 \mathrm{~b}$ & $0.06 \mathrm{a}$ & $0.00 \mathrm{a}$ & $0.00 \mathrm{a}$ \\
\hline 25-HC & $0.00 \mathrm{a}$ & $0.00 \mathrm{a}$ & $0.00 \mathrm{a}$ & $0.91 \mathrm{abc}$ & $1.21 \mathrm{c}$ & $1.03 b c$ & $0.69 \mathrm{abc}$ & $0.21 \mathrm{ab}$ & $0.00 \mathrm{a}$ & $0.00 \mathrm{a}$ \\
\hline 7-KC & $0.28 \mathrm{a}$ & $0.80 \mathrm{a}$ & $4.92 \mathrm{ab}$ & $37.82 \mathrm{~d}$ & $15.52 \mathrm{bc}$ & $14.94 b c$ & $20.28 \mathrm{c}$ & 9.30abc & $1.54 \mathrm{a}$ & $0.76 \mathrm{a}$ \\
\hline Total & $0.50 \mathrm{aA}$ & $1.89 \mathrm{aAB}$ & 9.10abAB & $60.39 \mathrm{dC}$ & $28.05 \mathrm{cB}$ & $17.34 \mathrm{abcA}$ & $21.97 \mathrm{bcA}$ & $9.87 \mathrm{abA}$ & $1.54 \mathrm{aA}$ & $0.76 \mathrm{aA}$ \\
\hline \multicolumn{11}{|l|}{$\mathrm{C}+\mathrm{TS}$} \\
\hline $7 \alpha-\mathrm{HC}$ & $0.00 \mathrm{a}$ & $0.35 \mathrm{a}$ & $0.54 \mathrm{a}$ & $1.91 \mathrm{a}$ & $3.37 \mathrm{a}$ & $8.29 b$ & $2.26 \mathrm{a}$ & $1.57 \mathrm{a}$ & $1.06 \mathrm{a}$ & $0.19 \mathrm{a}$ \\
\hline 7ß-HC & $0.00 \mathrm{a}$ & $0.35 \mathrm{ab}$ & $0.66 \mathrm{ab}$ & $2.80 \mathrm{~cd}$ & $4.76 \mathrm{e}$ & $7.41 \mathrm{f}$ & $3.92 \mathrm{~cd}$ & $2.73 \mathrm{~cd}$ & $1.83 b c$ & $0.55 \mathrm{ab}$ \\
\hline 及-EC & $0.00 \mathrm{a}$ & $0.80 \mathrm{a}$ & $2.10 \mathrm{ab}$ & $3.59 b c$ & $4.05 b c$ & $6.75 \mathrm{de}$ & $7.81 \mathrm{e}$ & $7.79 \mathrm{e}$ & $4.97 \mathrm{~cd}$ & $0.00 \mathrm{a}$ \\
\hline$\alpha-E C$ & $0.00 \mathrm{a}$ & $1.30 \mathrm{a}$ & $6.91 \mathrm{~b}$ & $5.87 \mathrm{~b}$ & $6.93 b$ & $8.56 \mathrm{~b}$ & $17.24 \mathrm{c}$ & $18.55 \mathrm{c}$ & $13.95 \mathrm{c}$ & $10.17 b c$ \\
\hline CT & $0.00 \mathrm{a}$ & $0.00 \mathrm{a}$ & $0.00 \mathrm{a}$ & 0.00 & 0.00 & 0.00 & 0.00 & 0.00 & 0.00 & 0.00 \\
\hline 25-HC & $0.00 \mathrm{a}$ & $0.00 \mathrm{a}$ & $0.00 \mathrm{a}$ & $0.15 b$ & $0.14 b$ & $0.26 \mathrm{c}$ & $0.26 \mathrm{c}$ & $0.26 \mathrm{c}$ & $0.11 \mathrm{~b}$ & $0.00 \mathrm{a}$ \\
\hline 7-KC & $0.00 \mathrm{a}$ & $1.67 \mathrm{ab}$ & $3.02 \mathrm{~b}$ & $7.54 \mathrm{c}$ & $9.60 \mathrm{c}$ & $17.86 \mathrm{~d}$ & $22.66 \mathrm{e}$ & $26.45 f$ & $24.10 \mathrm{e}$ & $16.91 \mathrm{e}$ \\
\hline Total & $0.00 \mathrm{aA}$ & $4.47 \mathrm{aB}$ & $13.23 \mathrm{bB}$ & $21.86 \mathrm{cB}$ & $28.86 \mathrm{cB}$ & $49.14 \mathrm{deC}$ & $54.15 \mathrm{deC}$ & $57.34 \mathrm{eE}$ & $46.03 \mathrm{dD}$ & $27.82 \mathrm{cB}$ \\
\hline \multicolumn{11}{|l|}{$\mathrm{C}+\mathrm{TO}$} \\
\hline $7 \alpha-\mathrm{HC}$ & $0.00 \mathrm{a}$ & $0.00 \mathrm{a}$ & $0.17 \mathrm{a}$ & $1.03 \mathrm{~b}$ & $2.85 \mathrm{c}$ & $7.90 \mathrm{e}$ & $9.15 \mathrm{f}$ & $10.15 \mathrm{~g}$ & $8.39 \mathrm{e}$ & $6.46 \mathrm{~d}$ \\
\hline 7及-HC & $0.00 \mathrm{a}$ & $0.00 \mathrm{a}$ & $0.23 \mathrm{a}$ & $1.49 \mathrm{~b}$ & $4.01 \mathrm{c}$ & $9.66 f$ & $10.91 \mathrm{~h}$ & $10.30 \mathrm{~g}$ & $7.76 \mathrm{e}$ & $6.21 \mathrm{~d}$ \\
\hline 及-EC & $0.00 \mathrm{a}$ & $0.00 \mathrm{a}$ & $0.00 \mathrm{a}$ & $0.86 \mathrm{~b}$ & $1.75 \mathrm{c}$ & $4.68 \mathrm{e}$ & $5.48 \mathrm{f}$ & $5.99 \mathrm{~g}$ & $4.94 \mathrm{e}$ & $4.20 \mathrm{~d}$ \\
\hline$\alpha-E C$ & $0.00 \mathrm{a}$ & $0.00 \mathrm{a}$ & $0.00 \mathrm{a}$ & $0.37 \mathrm{a}$ & $0.91 \mathrm{~b}$ & $2.64 \mathrm{c}$ & $3.45 \mathrm{~d}$ & $3.44 \mathrm{~d}$ & $2.77 \mathrm{c}$ & $2.92 \mathrm{c}$ \\
\hline CT & 0.00 & 0.00 & 0.00 & 0.00 & 0.00 & 0.00 & 0.00 & 0.00 & 0.00 & 0.00 \\
\hline 25-HC & $0.00 \mathrm{a}$ & $0.00 \mathrm{a}$ & $0.00 \mathrm{a}$ & $0.00 \mathrm{a}$ & $0.05 \mathrm{a}$ & $0.34 \mathrm{~b}$ & $0.48 \mathrm{c}$ & $0.54 \mathrm{c}$ & $0.51 \mathrm{c}$ & $0.30 \mathrm{~b}$ \\
\hline 7-KC & $0.00 \mathrm{a}$ & $0.00 \mathrm{a}$ & $0.40 \mathrm{a}$ & $2.02 \mathrm{ab}$ & $4.15 b$ & $8.83 \mathrm{e}$ & $12.89 \mathrm{~d}$ & $20.27 \mathrm{e}$ & $23.25 \mathrm{e}$ & $22.14 \mathrm{e}$ \\
\hline Total & $0.00 \mathrm{aA}$ & $0.00 \mathrm{aA}$ & $0.79 \mathrm{aA}$ & $5.76 \mathrm{bA}$ & $13.72 \mathrm{cA}$ & $34.05 \mathrm{~dB}$ & $42.37 \mathrm{eB}$ & $50.70 \mathrm{fD}$ & $47.62 \mathrm{fD}$ & $42.24 \mathrm{eC}$ \\
\hline \multicolumn{11}{|l|}{$\mathrm{C}+\mathrm{TL}$} \\
\hline $7 \alpha-\mathrm{HC}$ & $0.00 \mathrm{a}$ & $0.14 \mathrm{ab}$ & $0.15 \mathrm{ab}$ & $0.59 \mathrm{~b}$ & $1.35 \mathrm{c}$ & $2.92 \mathrm{~d}$ & $3.66 \mathrm{e}$ & $4.47 \mathrm{f}$ & $5.54 \mathrm{~g}$ & \\
\hline 7及-HC & $0.00 \mathrm{a}$ & $0.14 \mathrm{a}$ & $0.17 \mathrm{a}$ & $0.77 \mathrm{~b}$ & $1.90 \mathrm{c}$ & $4.40 \mathrm{~d}$ & $5.74 \mathrm{e}$ & $7.34 \mathrm{f}$ & $8.63 \mathrm{~g}$ & \\
\hline$\beta$-EC & $0.00 \mathrm{a}$ & $0.00 \mathrm{a}$ & $0.00 \mathrm{a}$ & $0.39 \mathrm{a}$ & $0.89 b$ & $2.09 \mathrm{c}$ & $2.70 \mathrm{~d}$ & $3.49 \mathrm{e}$ & $4.67 \mathrm{f}$ & \\
\hline$\alpha-E C$ & $0.00 \mathrm{a}$ & $0.00 \mathrm{a}$ & $0.00 \mathrm{a}$ & $0.00 \mathrm{a}$ & $0.64 b$ & $1.75 \mathrm{c}$ & $2.26 \mathrm{~d}$ & $2.71 \mathrm{e}$ & $4.36 \mathrm{f}$ & \\
\hline CT & $0.00 \mathrm{a}$ & $0.00 \mathrm{a}$ & $0.00 \mathrm{a}$ & $0.00 \mathrm{a}$ & $0.00 \mathrm{a}$ & $0.02 b$ & $0.08 \mathrm{e}$ & $0.04 \mathrm{c}$ & $0.05 \mathrm{~d}$ & \\
\hline 25-HC & $0.00 \mathrm{a}$ & $0.00 \mathrm{a}$ & $0.00 \mathrm{a}$ & $0.00 \mathrm{a}$ & $0.01 \mathrm{a}$ & $0.18 b$ & $0.26 \mathrm{c}$ & $0.39 \mathrm{~d}$ & $0.53 \mathrm{e}$ & \\
\hline 7-KC & $0.00 \mathrm{a}$ & $0.42 \mathrm{a}$ & $0.48 \mathrm{ab}$ & $0.96 \mathrm{~b}$ & $1.82 \mathrm{c}$ & $3.62 d$ & $5.27 \mathrm{e}$ & $7.89 \mathrm{f}$ & $11.92 \mathrm{~g}$ & \\
\hline Total & $0.00 \mathrm{aA}$ & $0.70 \mathrm{aA}$ & $0.80 \mathrm{aA}$ & $2.71 \mathrm{bA}$ & $6.61 \mathrm{cA}$ & $14.98 \mathrm{dA}$ & $19.97 \mathrm{eA}$ & $26.32 \mathrm{fC}$ & $35.70 \mathrm{gC}$ & \\
\hline \multicolumn{11}{|c|}{ C + TLn } \\
\hline $7 \alpha-\mathrm{HC}$ & $0.00 \mathrm{a}$ & $0.00 \mathrm{a}$ & $0.14 \mathrm{ab}$ & $0.69 \mathrm{~b}$ & $1.57 \mathrm{c}$ & $3.16 \mathrm{~d}$ & $3.74 \mathrm{e}$ & $4.58 \mathrm{f}$ & $4.53 \mathrm{f}$ & \\
\hline 7及-HC & $0.00 \mathrm{a}$ & $0.00 \mathrm{a}$ & $0.17 \mathrm{ab}$ & $0.74 b$ & $2.15 \mathrm{c}$ & $4.50 \mathrm{~d}$ & $5.53 \mathrm{e}$ & $6.42 \mathrm{f}$ & $6.74 f$ & \\
\hline $\boldsymbol{\beta}-\mathbf{E C}$ & $0.00 \mathrm{a}$ & $0.00 \mathrm{a}$ & $0.00 \mathrm{a}$ & $0.00 \mathrm{a}$ & $1.03 \mathrm{~b}$ & $1.19 \mathrm{~b}$ & $1.52 \mathrm{~b}$ & $1.58 \mathrm{~b}$ & $2.69 \mathrm{c}$ & \\
\hline$\alpha-E C$ & $0.00 \mathrm{a}$ & $0.00 \mathrm{a}$ & $0.00 \mathrm{a}$ & $0.00 \mathrm{a}$ & $0.59 b$ & $0.78 b c$ & $1.08 \mathrm{~cd}$ & $1.25 \mathrm{~d}$ & $2.40 \mathrm{e}$ & \\
\hline CT & $0.00 \mathrm{a}$ & $0.00 \mathrm{a}$ & $0.00 \mathrm{a}$ & $0.00 \mathrm{a}$ & 0.00 & 0.00 & 0.00 & 0.00 & 0.00 & \\
\hline 25-HC & $0.00 \mathrm{a}$ & $0.00 \mathrm{a}$ & $0.00 \mathrm{a}$ & $0.00 \mathrm{a}$ & $0.05 b$ & $0.18 \mathrm{c}$ & $0.24 d$ & $0.20 \mathrm{~cd}$ & $0.34 \mathrm{e}$ & \\
\hline 7-KC & $0.00 \mathrm{a}$ & $0.00 \mathrm{a}$ & $0.00 \mathrm{a}$ & $0.07 \mathrm{a}$ & $1.41 \mathrm{~b}$ & $2.31 \mathrm{c}$ & $3.86 \mathrm{~d}$ & $5.16 \mathrm{e}$ & $6.75 f$ & \\
\hline Total & $0.00 \mathrm{aA}$ & $0.00 \mathrm{aA}$ & $0.32 \mathrm{aA}$ & $1.51 \mathrm{bA}$ & $6.79 \mathrm{cA}$ & $12.12 \mathrm{dA}$ & $15.96 \mathrm{eA}$ & $19.20 \mathrm{fB}$ & $23.45 \mathrm{gB}$ & \\
\hline
\end{tabular}


a) Cholesterol + tristearin

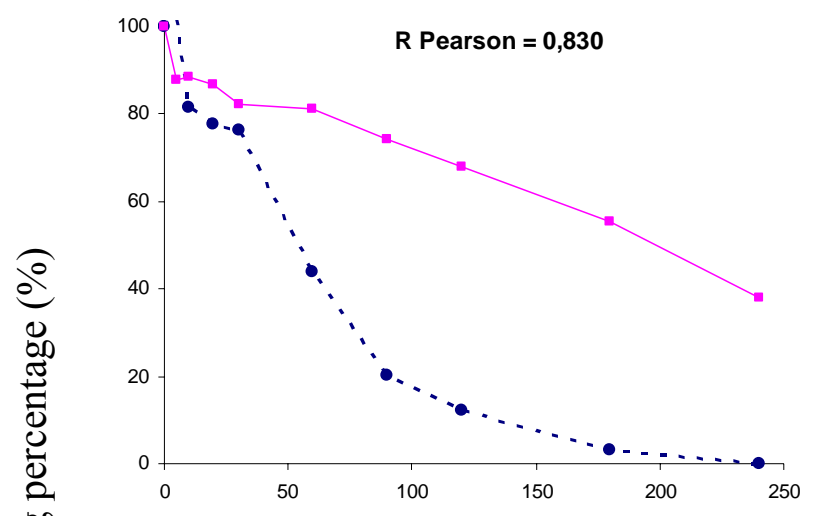

c) Cholesterol + trilinolein

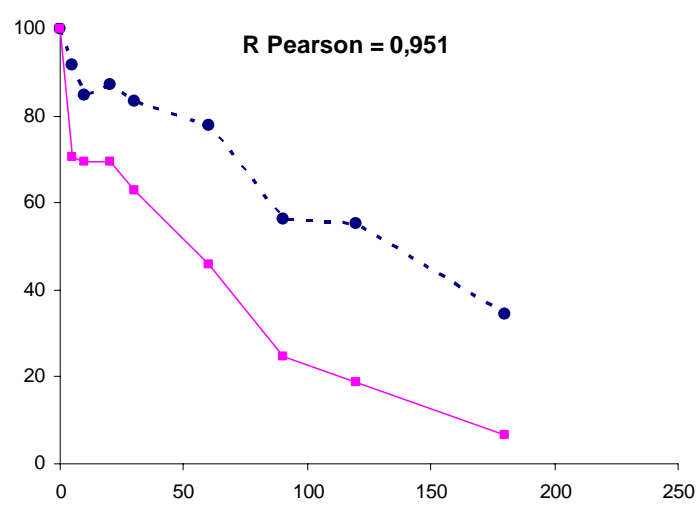

e) Cholesterol

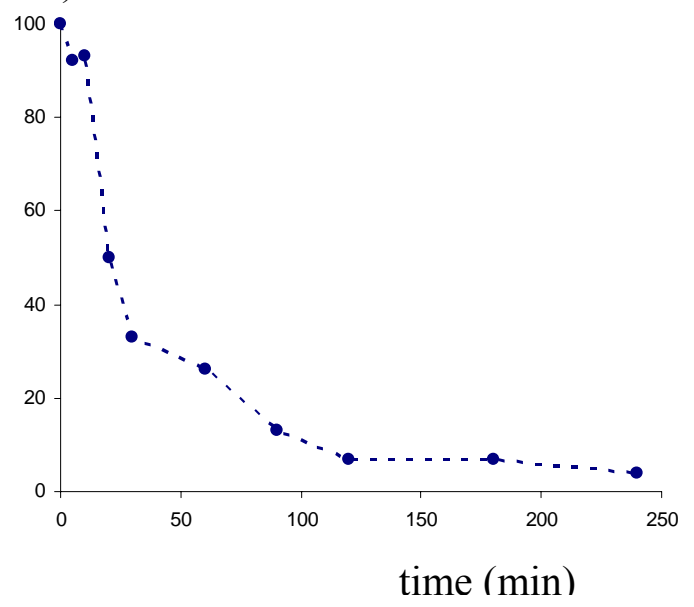

b) Cholesterol + triolein

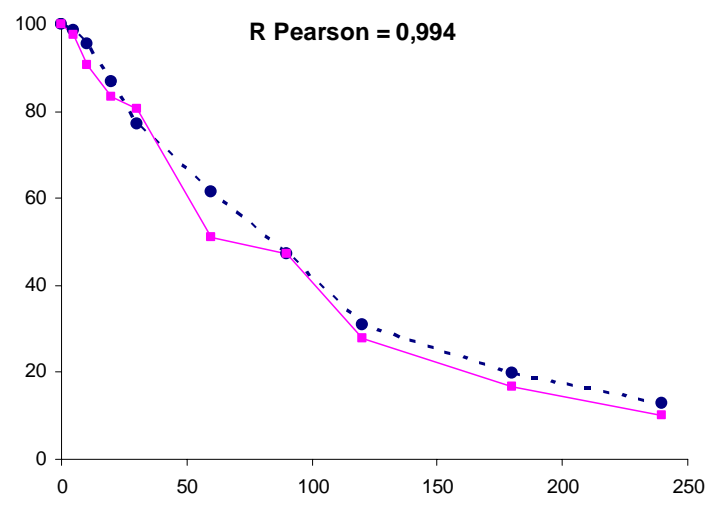

d) Cholesterol + trilinolenin

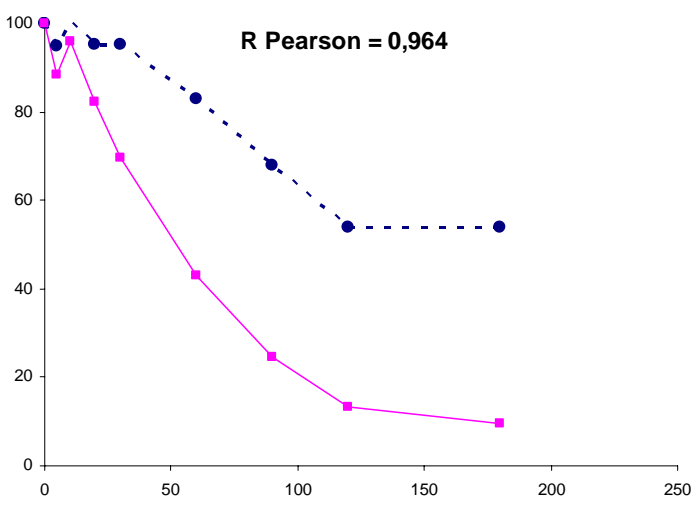

- -๑- - Cholesterol $\longrightarrow$ Triacylglycerols

Fig. 1. Remaining percentages of TAG and cholesterol during the heating treatment of the cholesterol+TAG mixtures (TS (a), TO (b), TL (c), TLn (d)) or cholesterol (e). Abbreviations: TS, tristearin; TO, triolein; TL, trilinolein; TLn; trilinolenin. 


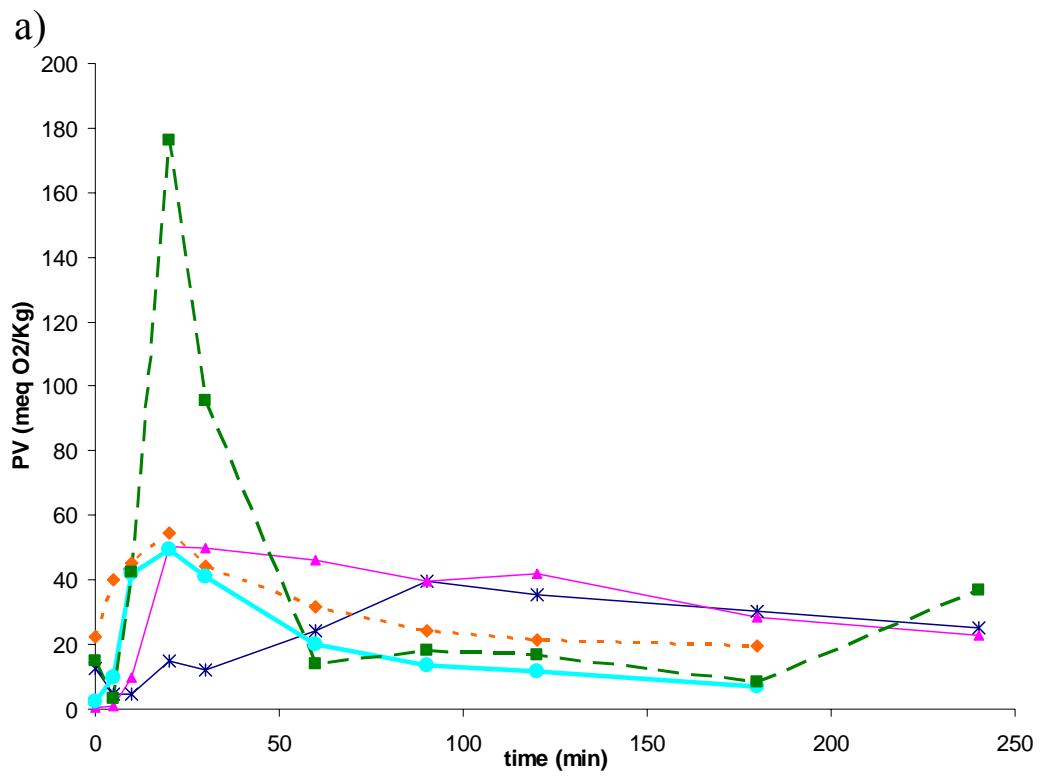

b)

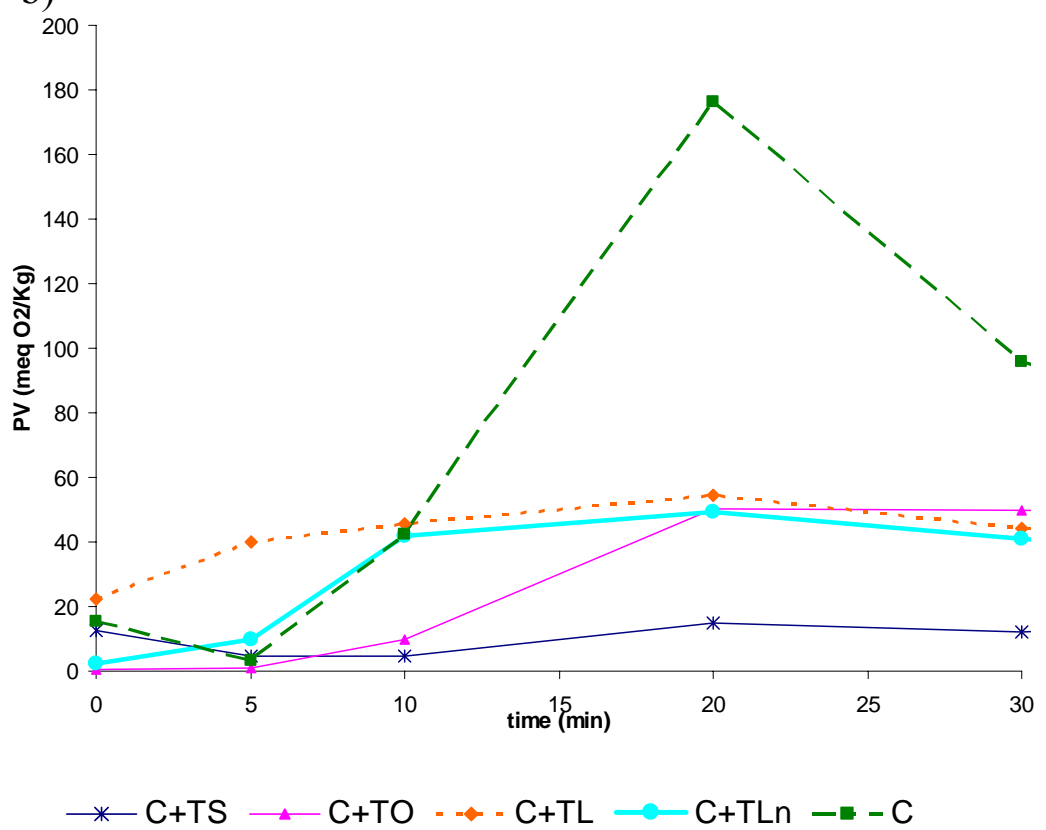

Fig. 2. Peroxides value of the mixtures of cholesterol+TAG and cholesterol alone during the whole heating treatment (a) and after the first $30 \mathrm{~min}$ (b). Abbreviations: C, cholesterol; TS, tristearin; TO, triolein; TL, trilinolein; TLn; trilinolenin. 


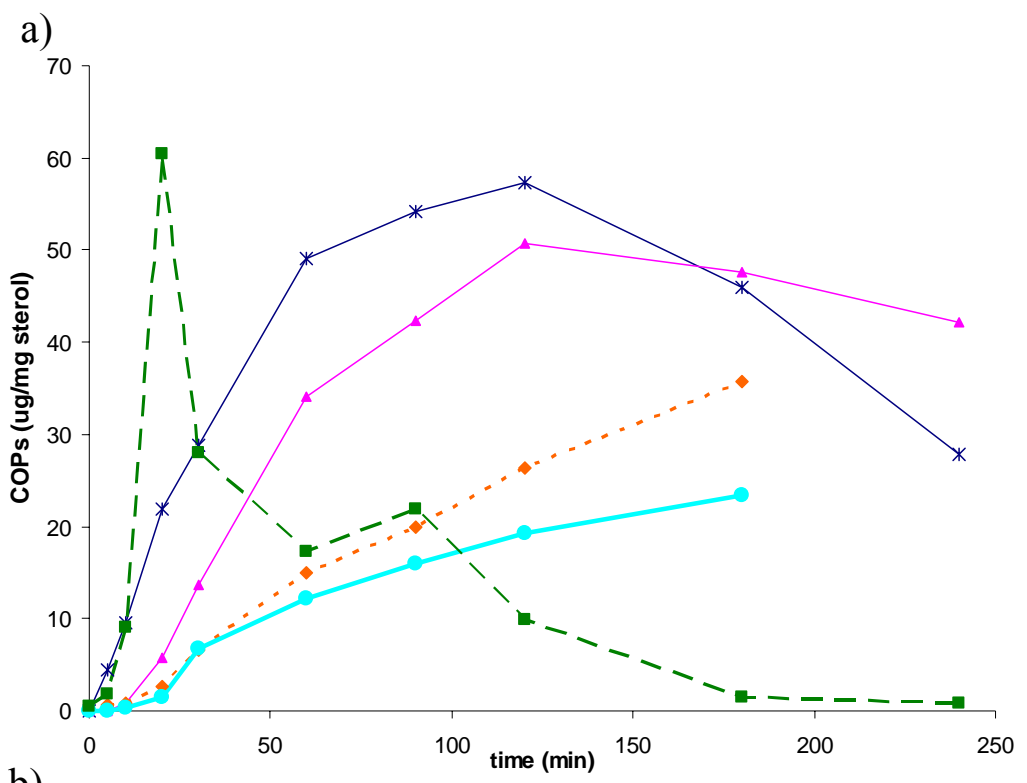

b)

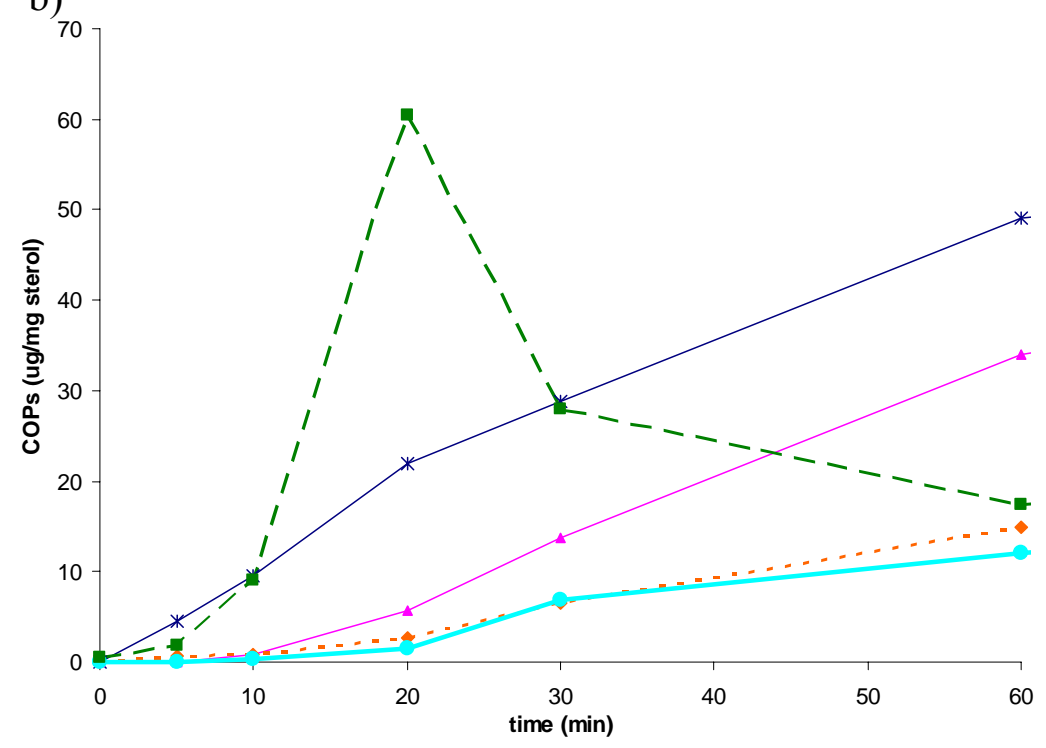

$\rightarrow \mathrm{C}+\mathrm{TS} \leadsto \mathrm{C}+\mathrm{TO} \rightarrow \mathrm{C}+\mathrm{TL} \longrightarrow \mathrm{C}+\mathrm{TLn}-\mathrm{C}$

Fig. 3. COPs in the mixtures of cholesterol+TAG and cholesterol alone during the whole heating treatment (a) and after the first 60 min (b). Abbreviations: C, cholesterol; TS, tristearin; TO, triolein; TL, trilinolein; TLn; trilinolenin. 